\title{
Cellular and molecular mechanisms of osteoporosis: current concepts and future direction treatment
}

\author{
Dolzhenko A.T. ${ }^{1}$, Sagalovsky S. ${ }^{2}$ \\ Biomedical Research Unit, Institute of Molecular Medicine Martin-Luther University Halle-Wittenberg, Germany ${ }^{1}$ \\ Department of Orthopedics Median Clinic², Bad Lausick, Germany
}

The article presents review of literature dedicated to the contemporary view on the cellular-molecular mechanisms of the bone remodeling and pathogenesis of the osteoporosis. The discovery of the cytokine RANKL-RANK-OPG system and significant role of the cathepsin $K$ in process bone remodeling has made progress in understanding the mechanisms development disease and possible to development drugs of the new generation - denosumab, a fully human RANKL monoclonal antibody and inhibitor cathepsin Kodanacatib that inhibits of the bone resorption.

Key words: osteoporosis, RANKL-RANK-OPG-signaling pathway; cathepsin K; denosumab; odanacatib.

Contact: Stanislav Sagalovsky; s.sagalovsky@gmail.com

For reference: Dolzhenko AT, Sagalovsky S. Cellular and molecular mechanisms of osteoporosis: current concepts and future direction treatment. Sovremennaya Revmatologiya=Modern Rheumatology Journal. 2016;10(2):56-63.

DOI: http://dx.doi.org/10.14412/1996-7012-2016-2-56-63

\begin{abstract}
Клеточно-молекулярные механизмы развития остеопороза: современные концепции и будущее направление терапии Долженко А.Т. ${ }^{1}$, Сагаловски С. ${ }^{2}$

${ }^{1}$ Институт молекулярной медицины, Университет им. Мартина Лютера Галле-Виттенберг, Германия; ${ }^{2}$ Отдел ортопедии клиники Медиан, Бад Лаузик, Германия
\end{abstract}

В обзоре литературы представлены современные взгляды на клеточно-молекулярные механизмы развития ремоделирования кости и патогенез остеопороза. Открытие цитокиновой системы RANKL-RANK-OPG и значительной роли катепсина K в процессе ремоделирования костной ткани способствовало значительному прогрессу в понимание механизмов развития остеопороза и позволило разработать препараты нового поколения - деносумаб, полностью человеческое моноклональное антитело к RANKL (гесерtor activator nucleus factor kappa B ligand), и ингибитор катепсина К оданакатиб, угнетающие процесс резорбции костной ткани.

Ключевые слова: остеопороз; RANKL-RANK-OPG-сигнальный путь; катепсин K; деносумаб; оданакатиб.

Контакты: Станислав Сагаловски; s.sagalovsky@gmail.com

Для ссылки: Долженко АТ, Сагаловски С. Клеточно-молекулярные механизмы развития остеопороза: современные концепции и будущее направление терапии. Современная ревматология. 2016;10(2):56-63.

Osteoporosis is characterized by increased bone turnover, low bone mass and an increased risk of fracture. The bone loss results from an imbalance between bone resorption and formation. Osteoporosis continues to be a major health problem. Approximately 200 million adults worldwide have osteoporosis [1, 2], and approximately $30 \%$ of all postmenopausal women in the Europe and the USA have osteoporosis [3]. Notwithstanding the availability of effective treatments for osteoporosis, such as the bisphosphonates (alendronate, risedronate, ibandronate and zoledronate), estrogen-based therapies, selective estrogen receptor modulators (raloxifene and bazedoxifene), parathyroid hormone and other niche treatments, including vitamin $\mathrm{D}$ derivatives and strontium (in some countries), many individuals with osteoporosis remain untreated. Although many individuals with osteoporosis remain undiagnosed, this lack of treatment may also reflect poor tolerability and mechanism-based toxicities of current therapies for osteoporosis. New therapies for osteoporosis that may potentially improve or augment existing therapies include the recently approved anti-Receptor Activator of NF-KappaB-ligand monoclonal antibody (denosumab/Prolia) and the cathepsin K (CatK) inhibitor odanacatib (ODN), presently in late stage clinical development.

\section{Cells involved in bone remodeling:} osteoblasts and bone formation

Bone is a dynamic tissue that undergoes continual adaption during life to attain and preserve skeletal size, shape and structural integrity and regulate mineral homeostasis. Two processes, remodeling and modeling, underpin development and maintenance of the skeletal system. Bone modeling is responsible for growth and mechanically induced adaption of bone and requires that the process of bone formation and bone resorption, while globally coordinated, occur independently at distinct anatomical location. This tightly coordinated event requires the synchronized activities of multiple cellular participants to ensure bone resorption and formation occur sequentially at the same anatomical location to preserve bone mass. Bone remodeling is a physiological process that maintains the integrity of the skeleton by removing old bone and replacing it with a young matrix. Two principle cell types are found in bone, the osteoclast, and the osteoblast, which are the major effectors in the turnover of bone matrix (Fig. 1) $[4,5]$. Osteoblasts and osteoclasts dictate skeletal mass, structure, and strength via their respective roles in resorbing and forming bone. Osteoblasts are specialized mesenchymal-derived cells 


\section{О БЗ О Р Ы}

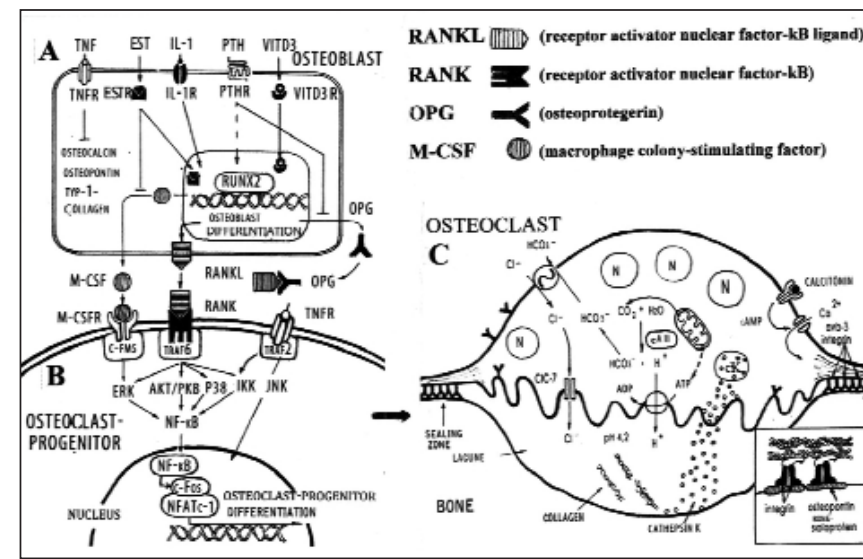

Fig. 1. RANKL-RANK-OPG system and regulation of osteoclast precursor by osteoblast $(A, B)$ and mechanisms of osteoclastic bone resorption $(C)$. Under physiologic condition, $R A N K L$ produced by osteoclasts binds to its receptor RANK on the surface of osteoclast precursors and recruits the adaptor protein TRAF6, leading to NF$k B$ activation and translocation to the nucleus. $N F-k B$ increases $c$ Fos expression and c-Fos interacts with NFATc 1 to trigger the transcription of osteoclastogenic genes. OPG inhibits the initiation of the process by binding to RANKL. The mechanisms of osteoclastic bone resorption (C): several transport systems including the $\mathrm{H}^{+}$-ATPase proton pump, $\mathrm{Cl} / \mathrm{HCO}_{3}$ exchanger and chloride channel are responsible for the acidification in the osteoclastic resorption lacune. The osteoclast attaches to bone, which promts formation of a convoluted ruffl ed membrane and a resorptive microenvironment beneath the cell. Hydrocarbonic acid, the product of a vacuolar-type $H^{+}$-ATPase and charge-coupled CL channel concentrated in the ruffled membrane, is secreted, resulting in mineral dissolution. Vesicles containing acidic collagenolytic enzymes in the form of cathepsins $K$, fuse with the bone-apposed membrane, leading matrix degradation. Intracellular $\mathrm{pH}$ balance is maintained by a passive $\mathrm{Cl} / \mathrm{HCO}_{3}$ exchanger on the contraresorptive surface of the cell. In the right corner: this fi gure summarized current information and hypotheses regulating the role of av $\beta_{3}$-integrin in osteoclast formation, adhesion, polarization and migration. The natural ligand for av $\beta_{3}$-integrin is not known, however osteopontin and bone sialoprotein are two $R G D$ (arginine-glycine-aspartate) containing proteins which could potentially be ligandes. See text for future details. Abbreviations: NFATc1, nuclear factor of activated $T$ cells; NF- $k B$, nuclear factor- $k B ; O P G$, osteoprotegerin; $R A N K L$, receptor activator of nuclear factor- $k B$ ligand; TRAF, tumor necrosis factor receptor associated factor

whose function is the deposition and maintenance of skeletal tissue. Osteoblasts derive from pluripotent mesenchymal stem cells (MCS) that prior to osteoblast commitment can also differentiate into other mesenchymal cells lineages such as fibroblasts, chondrocytes, myoblasts and bone marrow stromal cells including adipocytes, depending on the activated signaling transcription pathways. Understanding the mechanisms that control the differentiation of osteoblastic cells from MCS is thus one of the fundamental areas of research of bone biology. Several specific transcription factors are responsible for the commitment of pluripotent MSC into the osteoblast cell lineage [6]. Lineage-specific gene expression is ultimately under the control of transcription factors that act to regulate specifi c gene expression. They act as the key switching mechanisms to induce gene transcription. Considerable progress has been made in identifying those transcription factors which act as «master switches» during commitment of multipotent cells to specific lineages. A major break- through in understanding genetic regulation of osteoblast differentiation was made with the identification of the role of the transcription factor core binding factor 1 (Cbfa-1/RUNX-2) [7, 8]. Cbfa-1/RUNX-2 expression is an absolute requirement for osteoblast differentiation. In Cbfa-1 knockout mice there is a normal cartilaginous skeleton seen but a complete absence of bone formation [9]. Cbfa-1/RUNX-2 known to interact directly with the osteocalcin promoter to induce its expression [10]. However an additional transcription factor, Osterix, which is a downstream target for Cbfa1/RUNX-2, has also been shown to be an absolute requirement for normal osteoblast differentiation in knockout mice experiments [11]. More recent studies have shown the existence of distinct isoforms of Cbfa-1, which may have subtly different roles during normal tissue formation, including regulation of cartilage expression in addition to bone. Another runt-related gene that plays an important role in the commitment of multipotent MSC to the 1/RUNX-2, has also been shown to be an absolute requirement for normal osteoblast differentiation in knockout mice experiments [11]. More recent studies have shown the existence of distinct isoforms of Cbfa-1, which may have subtly different roles during normal tissue formation, including regulation of cartilage expression in addition to bone. Another runt-related gene that plays an important role in the commitment of multipotent MSC to the osteoblastic lineage and for osteoblast differentiation at an early stage is RUNX-2. Cbfa-1/RUNX-2 are involved in the production of bone matrix proteins [12], as it is able to up-regulate the expression of major bone matrix protein genes, such as type I collagen, osteopontin, bone sialoprotein and osteocalcin leading to an increase of immature osteoblasts from MCS; the immature osteoblasts from immature bone [13]. Osteoblast commitment, differentiation and growth are controlled by several local and systemic factors that can also act in a paracrine and/or autocrine way and that can regulate the activity of specific transcription factor [14]. Huge advances have been made in the understanding of cellular and molecular control of bone formation in the past decade. The establishment of in vitro models of osteoblast differentiation and formation has been essential for determining the effects of specific growth factors and growth factor-induced transcription factors on osteogenesis. Osteoblasts play a crucial role in the process of bone formation, in the induction and regulation of extracellular matrix mineralization and in the control of bone remodeling [15]. During bone formation, mature osteoblasts synthesize and secrete type I collagen (which represents the greated part of the organic extracellular bone matrix) and various non-collagen proteins such as osteocalcin, osteopontin and bone sialoprotein (which exert various essential functions, including the regulation of bone turnover, the control of bone mineral deposition and regulation of bone cell activity). Osteocalcin (Gla) is a vitamin-Kdependent osteoblast-specific protein and whose synthesis is enhanced by 1,25 $\mathrm{OH}$ vitamin $\mathrm{D}_{3}$ and reflects metabolic cellular activity. Of the de novo synthesized osteocalcin, 60-90\% is incorporated into the bone matrix where it binds to hydroxyapatite during matrix mineralization. Osteopontin (OPN) is a phosphorylated acidic glycoprotein that is present in large amounts in immature bone. OPN is synthesized by osteoblast but is expressed by other cellular types, such as chondrocytes; it is involved in various physiological and pathological events. Bone sialoproteins I glycosylated, phosphorylated and sulfated protein that promotes hydroxyapatite crystal nucleation and osteoblast differentiation [16]. This has been confirmed by the observation that bone-sialo- 
protein-knockout mice present hypo-mineralized bone, a reduction in the size of their long bones and aberrant levels of osteoblast markers [17]. Osteoblasts also synthesize cytokine interleukin-1 (IL-1) and interleukin-6 (IL-6), which control bone cells in an autocrine and/or paracrine manner. Various in vitro studies of human and murine osteoblastic cell lines suggest that IL-1 can affect proliferation, collagen and osteocalcin synthesis and alkaline phosphatase production [18]. Osteoblasts express receptors for various hormones including parathyroid hormone (PTH) [19], 1,25 $(\mathrm{OH})_{2} \mathrm{D}_{3}$ [20], estrogenes [21], which are involved in the regulation of osteoblast differentiation and activity. Vitamin $\mathrm{D}_{3}$ is able to modulate the metabolic activity of osteoblasts through the activation of a series of Vitamin- D-responsive genes that reflect a more mature osteoblast phenotype.

\section{Control of bone remodeling by osteoblasts: the role RANKL-RANK-OPG system of the osteoclast development}

In recent years it has become evident that osteoblasts have a global role in orchestrating the bone remodeling process. Their function is not restricted solely to bone formation, but it is now firmly established that they are responsible for initiating bone resorption. In cellular terms, apart from forming the mineral and organic extracellular compartment of bone, the osteoblast provides the essential and sufficient stimuli that control the behavior of the osteoclast, an event that occurs via cell-cell interaction. The bone resorption cascade involves a series of steps directed towards the removal of both the mineral and organic constituents of bone matrix by osteoclasts, aided by osteoblasts (Fig. 1). The role of the osteoclast as a major resorbing cell, and its structure and biochemical properties have been well characterized [22, 23]. The first stage involves the recruitment and dissemination of osteoclast progenitors to bone. The progenitor cells are recruited from the haemopoietic tissue such as bone marrow and slenic tissue to bone via the circulating blood stream. They proliferate and differentiate into osteoclasts through a mechanism involving cellto-cell interaction with osteoblast stromal cells. Osteoclast formation from osteoclast precursor is regulated predominantly by osteoblastic cells during normal bone remodeling. Osteoblastic cells in the bone marrow express two cytokines that are required for osteoclast-progenitor differentiation into osteoclasts: receptor activator of NF-kB ligand (RANKL) and osteoprotegerin (OPG) [24] (Fig. 1, A). The discoveries of the receptor activator of NF$\mathrm{kB}$ ligand and osteoprotegerin have revolutionized our understanding of the process underlying osteoclast formation and activation [25, 26]. RANKL and OPG potently stimulate and inhibit, respectively, osteoclast differentiation. RANKL is a membrane bound factor that is produced by osteoblasts and stromal cells in response to a variety of signals such as parathyroid hormone (PTH), tumor necrosis factor- $\alpha$ (TNF- $\alpha$ ) and Il-1. RANKL bind to the cytoplasmic membrane receptor RANK (receptor activator of NF-kB), which is a member of the tumor necrosis factor (TNF) receptor super family and subsequently induces both osteoclast differentiation and activation. OPG is a soluble decoy receptor for RANKL and can inhibit its effects, thereby preventing osteoclast development and subsequent bone resorption [27]. Over expression of OPG in transgenic mice results in osteopetrosis, and, conversely, OPG deficient mice exhibit severe osteoporosis. Many of the same agent that stimulate RANKL expression (including PTH, IL-1, PGE) also inhibit OPG expression $[28,29]$, which enhances osteoclastogenesis even further. While FGF-2 induces RANKL expression by osteoblasts, it also inhibits osteoclast differentiation directly by interfering with the action of macrophage colony stimulating factor (M-CSF) [30]. In contrast, to the stimulatory effects of the agents described above, estrogen inhibits the production of RANKL by osteoblasts [31]. Transforming growth factor- $\beta$ (TGF- $\beta$ ) also strongly suppresses RANKL expression by osteoblasts, whereas it stimulates OPG expression [32]. Administration of RANKL to mice causes osteoporosis, whereas disruption of the RANKL gene in mice leads to severe osteopetrosis, impaired tooth eruption, and the absence of osteoclasts [33]. Membrane bound macrophage colony stimulating factor (M-CSF) is also a critical early modulator in the differentiation of osteoclasts [34]. M-CSF binds to c-Fms on the surface of osteoclast precursors, and this event enhances their proliferation and survival. M-CSF enhances the survival of monocyte stem cells thereby permitting them to respond to direct inducers of differentiation such as RANKL. A combination of MCSF and RANKL is sufficient for human, mouse, and rat multinucleated osteoclast formation in vitro (Fig. 2, b) [34]. Although RANKL is critical for osteoclast formation and activation, a series of complementary studies has revealed a number of additional gene products that are necessary for osteoclastogenesis and a variety of hormones and cytokines that modulate osteoclast formation [23, 35]. Deletion of the genes for M-CSF, c-fos, RANK and NF-kB results in absent osteoclast formation confirming their requirement for osteoclastogenesis. Osteoclasts are formed in mice whom the genes for TRAF6 (TNF receptor activating factor 6) and the c-fos have been deleted; however, these osteoclasts exhibit defects in bone resorption resulting in osteopetrosis [36]. Interestingly, another TRAF6 knockout mice exhibits defective osteoclastogenesis. TRAF6 activates the MAP kinase cascade, and eventually activates JNK, JKK and N-kB have been directly implicated in the response to RANKL [37] (Fig. 1, b). Different domains of TRAF6 modulate both the initial differentiation and subsequent maturation of osteoclasts by activating various kinase cascades. RANKL also activates NF-kB in osteoclasts, in large part via TRAF stimulation of Ik kinase (IKK) to phosphorylate IkB, which then dissociates from NF-kB, and permits NF-kB translocation into the nucleus and subsequent binding to NF-kB responsive genes. TNF- $\alpha$ also acts to induce osteoclast formation and activation in concert with RANKL via the TNF receptor and TRAF2 $/ 6$ and subsequently to activate NF-kB signaling [38].

\section{Osteoclast and bone resorption}

The development of an in vitro bone resorption model using isolated primary osteoclasts and mineralized bone matrix as a substrate almost twenty years ago provided an excellent system for detailed cell biological studies of bone resorption [39]. Although this model has several limitations in attempts to study the whole physiological cascade of bone resorption, it provides an excellent tool for detailed studies of the cellular mechanisms involved in the destruction of mineralized bone matrix. The sequence of cellular events needed for bone resorption is called the resorption cycle. Resorption requires cellular activates : migration of the osteoclast to the resorption site, its attachment to bone, polarization and formation of new membrane domains, dissolution of hydroxyapatite, degradation of organic matrix, removal of degradation products from the resorption lacuna, and finally either apoptosis of the osteoclasts or their return to the nonresorbing stage (Fig. 1, C). The term resorption cycle covers neither the differentiation pathway nor the cellular activities needed for the 


\section{О БЗ $О$ Р Ы}

fusion of mononuclear precursor to form the multinuclear mature osteoclast. It should not be mistaken for the more widely used term remodeling cycle, which is used to describe the bone remodeling at the tissue level that involves the activities of several different cell types. After migration of the osteoclast to a resorption site, a specific membrane domain, the sealing zone, forms under the osteoclast. The plasma membrane attached tightly to the bone matrix and seals the resorption site form its surroundings . The molecular interactions between the plasma membrane and the bone matrix at the sealing zone is still unknown. Several lines of evidence have shown, however, that integrins play an important role in early phases of the resorption cycle [40]. At last four different integrins are expressed in osteoclasts: $\alpha v \alpha_{3}, \alpha v \alpha_{5}, \alpha_{2} \beta_{1}$ and $\alpha v \beta_{1}[40,41]$. The role of $\alpha v \beta_{3}$ has received much attention, because antibodies against $\alpha v \beta_{3}$, as well as argynine-glycineaspartic acid (RGD)-containing peptides such as echistation and kistrin, are defective inhibitors of bone resorption both in vitro and in vivo [41]. $\alpha v \beta_{3}$ is highly expressed in osteoclasts and is found but what the plasma membrane and in various intracellular vacuoles. However, the precise function of $\alpha v \beta_{3}$ in resorbing osteoclasts remains unknown; the integrin could play a role both in adhesion and migration of osteoclasts and in endocytosis of resorption products. The latter possibility is supported by the observation that high amount of $\alpha v \beta_{3}$ are present at the ruffled border and by recent data from receptor-binding assays showing that denatured type I collagen has a high affinity for $\alpha v \beta_{3}$. Some authors have suggested that $\alpha v \beta_{3}$ integrin also mediates the attachment of the sealing zone to the bone matrix [41]. Previous ultrastructural studies indicated that resorbing osteoclasts are highly polarized cells. Current data suggest that resorbing osteoclasts contain not only the sealing zone but also at least three other specialized membrane domains: a ruffled border, a functional secretary domain and a basolateral membrane [42]. As the osteoclast prepares to resorb bone, it attaches to the bone matrix through the sealing zone and forms another specific membrane domain, the ruffled border. The ruffled border is a resorbing organelle, and it is formed by fusion of intracellular acidic vesicles with the region of plasma membrane facing the bone [42]. During this fusion process much internal membrane is transferred, and forms long, finger-like projections that penetrate the bone matrix. The characteristics of the ruffled border to not match those of any other plasma membrane domain described. Although facing the extracellular matrix, it has several features that are typical of late endosomal membranes. Several late endosomal markers, such as CIC-7, V-type $\mathrm{H}^{+}$-ATPase, are densely concentrated at the ruffled border [43]. The main physiological function of osteoclast is degrading mineralized bone matrix. This involves dissolution of crystalline hydroxyapatite and proteolytic cleavage of the organic matrix, which is rich in collagen. Before proteolytic enzymes can reach and degrade collagenous bone matrix, tightly packed hydroxyapatite crystals must be dissolved. It is now generally accepted that the dissolution of mineral occurs by targeted secretion of $\mathrm{HCl}$ through the ruffled border into the resorption lacuna. This is an extracellular space between the ruffled border membrane and the bone matrix, and is sealed from the extracellular fluid by the sealing zone. The low $\mathrm{pH}$ in the resorption lacuna is achieved by the action of ATP-consuming vacuolar proton pumps both at the ruffled border membrane and in intracellular vacuoles. Osteoclasts attach to bone and form a circumferential sealing zone that isolates the bone resorption compartment from the extracellular space. Osteoclast plasma membrane within the seal- ing zone develops into the ruffled border. The observation that $\mathrm{NH}_{4} \mathrm{Cl}$ reversibly inhibits bone resorption by osteoclasts indicates that the resorption compartment is acidic and that the sealing zone is impairment to $\mathrm{H}^{+}$and $\mathrm{NH}^{+}$. The osteoclast cytoplasm is rich in carbonic anhydrase [25, 44], proving a continuous supply of protons and bicarbonate. Protons are transported across this membrane into the bone resorption compartment by vacuolartype $\mathrm{H}^{+}$-ATPase (V-type ATPase). Chloride ions passively follow the protons through conductive anion channels. The combined activities of the proton pump and chloride channel acidify the resorption compartment and alkalinize the cytoplasm. Bicarbonate exits the cell into the extracellular space in exchange for chloride via a basolateral electroneutral anion exchanger, correcting the cytoplasmic alkalinization and compensating for cytoplasmic chloride loss. The net result of these coordinated transport activities is the transcellular movement of $\mathrm{HCl}$ into the bone resorption compartment. This model predicts that both the ruffled border proton pump and chloride channel play key roles in bone resorption. The proton pump provides the proton-motive force necessary to generate a $\mathrm{pH}$ gradient. However, the pump is electrogenic. The chloride channel shot-circuits the electrogenic pump and allows maximal proton transport. It follows that limitation of the chloride conductance could inhibit acid transport independently of the intrinsic activity of the proton pump. Analogous to a current model for regulation of the $\mathrm{pH}$ of some intracellular organelles, regulation of the anion conductance rather than proton pump activity could be the key point at which the rate of osteoclast acid transport, and hence bone resorption, is governed. Thus, molecular characterization of the ruffled border chloride channel may provide insight into regulation of osteoclast bone resorption and could define a pharmacological target for the treatment of metabolic bone disease. The osteoclast proton pump is sensitive to bafilomycin A1, which also effectively inhibits bone resorption both in vitro and in vivo. The recent finding that vacuolar ATPase at the ruffled border contains cells specific subunits has further encouraged development of resorption inhibitors that inhibit the osteoclast proton pump. Protons for the proton pump are produced by cytoplasmic carbonic anhydrase II, high levels of which are synthesized in osteoclasts. In order to generate protons, the presence of carbonic anhydrase II (CA II) is essential. It catalyzes the conversion of $\mathrm{H}_{2} \mathrm{O}$ and $\mathrm{CO}_{2}$ into $\mathrm{H}_{2} \mathrm{CO}_{3}$, which then is ionized into $\mathrm{H}^{+}$and $\mathrm{HCO}_{3}^{-}$. Mutation in CA II can cause osteopetrosis due to non-functional osteoclasts [45]. The $\mathrm{HCO}_{3}^{-}$ions are exchanged for $\mathrm{Cl}^{-}$through an anion exchanger, membrane transport protein AE2, located in the basolateral membrane, leading to continued of $\mathrm{Cl}^{-}$for acidification of the resorption lacuna. After solubilization of the mineral phase, several proteolytic enzymes degrade the organic bone matrix, although the detailed sequence of events at the resorption lacuna is still obscure. Two major classes of proteolytic enzymes, lysosomal cysteine proteinases and matrix metalloproteinases (MMPs) have been studied most extensively. Osteoclasts produce proteases, of which cysteine proteinase cathepsin $\mathrm{K}$ has prevent to be the most important [46], aiding the degradation of the organic bone matrix. Eleven different types have been described (B, C, F, H, K, $\mathrm{L}$ and other) with cathepsin $\mathrm{K}$ being the most important with respect to bone remodeling, since it is a protease with intense collagenase activity, especially with respect to acid $\mathrm{pH}$, which is essential to dissolve calcic hydroxyapatite, the main mineral component of bone. It degrades the two types of collagen, I and II and is predominantly expressed in osteoclasts. Cathepsin $\mathrm{K}$ gives rise 


\section{О БЗ 30 Р Ы}

to specific degradation products-like C-terminal cross-linking telopeptide of type I collagen (CTX-I), which can be used for measurements of bone resorption [46]. The role of cathepsin $\mathrm{K}$ in bone resorption was determined using evidence from an autosomal recessive osteochondrodysplasia named pycnodysostosis, a very rare disease characterized by high bone mineral density, acroosteolysis of the distal phalanxes, shot stature, and cranial deformaties with late closing of the fontanelles [47]. Studies in mice submitted to nonfunctional mutations of cathepsin have given rise to different models of osteopetrosis. Matrix in bone resorption, during which, MMP activity is known to give rise to a specific degradation fragment, C-terminal telopeptide of type I collagen (ICTP) [46]. After matrix degradation, the degradation products are removed from the resorption lacuna through a transcytotic vascular pathway from the ruffled border to the functional secretory domain, where they are liberated into the extracellular space. Quantitative data are still missing, but clear large amounts of degraded extracellular material must be transported through the resorbing cell, given that the volume of the resorption pit can easily exceed the volume of the entre cell. The extent to which the degradation of collagen and other matrix components is extracellular and the extent to which this takes place in intracellular transcytotic compartments are not known. Recent results have suggested that tartrate-resistant acid phosphatase (TRAP), a widely used osteoclast marker, is licalized in the transcytotic vesicles of resorbing osteoclasts, and that it can generate highly destructive reactive oxygen species able to destroy collagen. This activity, together with the co-localization of TRAP and collagen fragments in transcytotic vesicles, suggests that TRAP functions in further destruction of matrix-degradation products in the transcytotic vesicles. The observed mild osteopetrosis in TRAPknockout mice support this hypothesis [48].

\section{New therapeutic strategies for bone resorption inhibition}

Currently available therapies for postmenopausal osteoporosis either aim at correcting the estrogen deficit (HRT, SERM), specifically target osteoclasts (calcitonon, bisphosphonates) or stimulate bone formation (fluoride). Better understanding of the molecular processes of bone remodeling $[4,23]$ has led to the development of agents to inhibits bone resorption, such as the human monoclonal antibody - denosumab [49] and inhibitor enzyme cathepsin K odenacatib [50].

\section{$R A N K L$-inhibitor denosumab}

Denosumab, the first in class RANKL-inhibitor, is a recombinant human $\operatorname{IgG}_{2}$ antibody with affinity and specificity for RANKL. By binding to RANKL, denosumab prevents the RANKL/RANK interaction on the osteoblast which leads to the inhibition of osteoclast formation, function, and survival, thereby decreasing bone resorption and increasing bone mass and strength in both cortical and trabecular bone. The 3-year, randomized, double-blind, placebo-controlled fracture endpoint trial FREEDOM enrolled 7808 women between the ages of 60 and 90 years (mean 72 years) who had a baseline BMD T-score between $-2,5$ and $-4,0$ at either the lumbar spine or total hip. The mean baseline lumbar spine BMD T-score was -2,8 SD, and $23 \%$ of women had a vertebral fracture at baseline. Women were randomized to receive SC injections of either placebo $(\mathrm{N}=3906)$ or denosumab $60 \mathrm{mg}$ $(\mathrm{N}=3902)$ once every 6 months. All women received at least $1000 \mathrm{mg}$ calcium and $400 \mathrm{IU}$ vitamin D supplementation daily. Denosumab significantly reduced the incidence of new morphometric vertebral fractures (primary endpoint) at 3 years $(7,2 \%$ vs $2,3 \%-68 \%$, $\mathrm{p}<0,0001)$. In addition, denosumab significantly reduced the incidence of hip and non-vertebral fractures (secondary endpoints) at 3 years $(1,2 \%$ vs $0,7 \%-40 \%, p=0,04$ and $8,0 \%$ vs $6,5 \%-20 \%$, $\mathrm{p}=0,01$, respectively) [51]. Furthermore, the antifracture efficacy of denosumab was consistent across patients with varying degrees of fracture risk. Denosumab was generally well tolerated. Based on postmarketing and clinical research experience available to date, denosumab exposes patients to a risk of hypocalcaemia, which is significant in patients with severe renal impairment or receiving dialysis, to a potential for adverse outcomes resulting from the induced profound, even if reversible, suppression of bone remodelling such as osteonecrosis of the jaw, atypical fractures and delayed fracture healing, and to a potentially increased risk of severe infections consistent with its osteoimmunological effects. Epidermal and dermal adverse events not specific to the injection site (such as dermatitis, eczema, and rashes) were significantly increased. Finally, cases of pancreatitis and new malignancies of the breast, the reproductive system, and the gastrointestinal system were numerically more frequent with denosumab with no established causal relationship to drug exposure. Denosumab was also proven effective for increasing BMD over 2 years in women receiving adjuvant aromatase inhibitor therapy for breast cancer and for increasing BMD and reducing the incidence of vertebral fractures over 3 years in men with non-metastatic prostate cancer receiving androgen deprivation therapy.

\section{Cathepsin K inhibitor odanacatib}

Odanacatib is the most advanced cathepsin $\mathrm{K}$ inhibitor currently under development. Odanacatib was shown to be orally bio-available, highly selective for and reversibly binding to cathepsin K [50, 52]. Based on phase I and II results, the recommended dosage is $50 \mathrm{mg}$ once weekly per os [53]. The increases in spine and hip BMD observed with odanacatib were comparable to those observed with the bisphosphonate zoledronate and the RANKL-inhibitor denosumab [52]. The effect of odanacatib was compared with placebo in a small phase III trial dedicated to evaluating the effect of odanacatib with the latest bone imaging techniques including QCT at the hip and lumbar spine (Fig. 2), and high resolution peripheral (HRp) QCT at the distal radius and tibia, along with the classical measures of areal BMD using dual energy X-ray absorptiometry (DXA) and of biochemical markers of bone turnover, among 214 postmenopausal with low areal BMD. As early as 6 months, odanacatib-treated women had greater increases in trabecular volumetric BMD and estimated compressive strength at the spine compared with placebo; integral and trabecular volumetric BMD and estimated strength at the hip also improved. At the femoral neck cortex, bone mineral content, thickness, volume and cross-sectional area also increased from baseline with odanacatib versus placebo over the entire course of the trial [54]. At the distal radius and tibia, total volumetric BMD (vBMD), trabecular vBMD, cortical vBMD, cortical thickness and strength estimated using FEA showed significantly greater improvements with odanacatib compared with placebo. At the hip, the trabecular and cortical compartment were similarly affected by the gains in bone mineral content [55]. The magnitude of these microarchitectural evaluated the same way, although no head-to-head comparison has been made.In another trial, the effect of odanacatib taken after alendronate has been examined. In this randomized, double-blind, placebo-controlled, 24-month study, 243 postmenopausal women aged at least 60 years, with low 
О Б 30 Р Ы

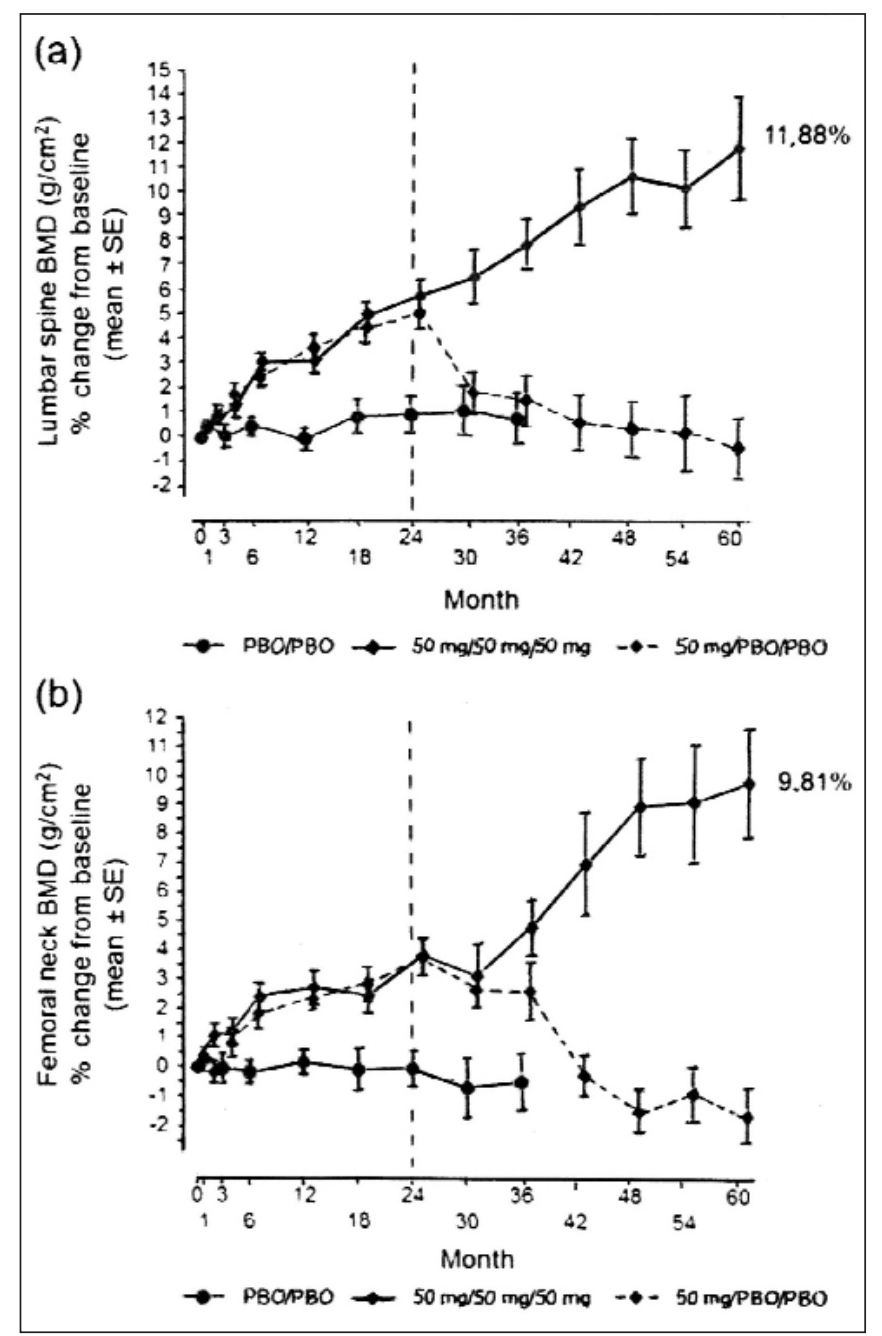

Fig. 2. Mean percentage change from baseline over time for the fullanalysis-set population in lumbar spine BMD (a) and femoral neck $B M D(b)$ at 5 years for three of the randomization groups. $50 \mathrm{mg}$, odanacatib 50 mg once weekly; BMD, bone mineral density; $P B O$, placebo once weekly; SE, standard error. (Adapted from [56])

BMD at the total hip, femoral neck or trochanter ( $T$ score $\leqslant-2,5$ but $>-3,5$ without prior fracture or $\leqslant-1,5$ but $>-3,5$ with prior fracture) who had taken alendronate for $\geqslant 3$ years were allocated to receive odanacatib or placebo [54]. In the odanacatib group, BMD changes from baseline at the femoral neck, trochanter, total hip and lumbar spine at 24 months $(1,7,1,8,0,8$ and 2,3\%, respectively) were significantly different from the group switched to placebo, but the variation at the radius did not differ significantly between the two groups. As in prior reports of bisphosphonate-naïve patients, urinary NTX decreased with odanacatib. The level of beta CTX, however, increased unexpectedly. This might be explained by predominantly metalloproteinase-mediated bone resorption of older bone, which predominates in case of inhibition of CatK, while the inhibition of the resorption of younger bone seemed to continue, as shown by reduced levels of alpha CTX. The main outcome for registration of anti-osteoporosis drugs is the another trial, the effect of odanacatib taken after alendronate has been examined. reduction in fracture incidence. A phase III trial - still unpublished and only presented in a scientific meeting - involving 16,713 postmenopausal women $\geqslant 65$ years of age with low BMD has been conducted to prove the antifracture efficacy of odanacatib. Women were randomized to receive weekly odanacatib $50 \mathrm{mg}$ or placebo for 3 years. The primary outcomes were time to first morphometric (radiographically assessed) vertebral fracture, time to first hip fracture and time to first hip

fracture and time to first clinical nonvertebral fracture. This trial was event-driven, so that it has been stopped after an interim analysis has shown robust reduction in vertebral and hip fracture incidence. The mean age at enrolment was 72 and $46 \%$ of these women had at least one prevalent vertebral fracture. There was a $54 \%$ relative risk reduction of new and worsening morphometric vertebral fractures, a $47 \%$ relative risk reduction of clinical hip fractures, a $23 \%$ relative risk reduction of clinical nonvertebral fractures and a $72 \%$ relative risk reduction of clinical vertebral fractures. Interestingly, while there was a smaller reduction in markers of bone resorption in comparison with other powerful antiresorptive agents, the reduction in levels of formation markers was much smaller [56]. Furthermore, histomorphometry of bone biopsies performed in a subset of 32 patients included in the phase II trial showed that the modest reduction in bone formation markers was not accompanied by a suppression of the bone formation rate. These findings suggest a decoupling between bone formation and resorption. It was hypothesised that as the inhibition of cathepsin K suppresses osteoclast function but does not impair osteoclast viability, it may preserve the osteoclastosteoblast crosstalk and maintain bone formation [57]. In addition, unlike conventional antiresorptives, odanacatib displayed site specific effects on trabecular versus cortical bone formation with marked increases in periosteal bone formation and cortical thickness in ovariectomised monkeys [58]. Although their clinical relevance remains to be confirmed, these findings would represent a major advance in the field of bone research. A randomised, placebo-controlled phase III fracture endpoint trial, which has enrolled more than 16000 postmenopausal women with low bone mass, is currently ongoing with expected results during summer 2012 (NCT00529373). Once available, the results of this study will unveil a comprehensive efficacy and safety profile of odanacatib for the treatment of postmenopausal osteoporosis [59, 60]. The US Food and Drug Administration (FDA) submission is expected to occur in 2015 after gathering more follow-up data.

\section{Conclusions}

Denosumab is a fully human $\mathrm{IgG}_{2}$ antibody that binds to RANK ligand with very high specificity. By preventing the interaction of RANK ligand to its receptor RANK, denosumab is a potent anti-resorptive agent, decreasing the formation, function, and survival of osteoclasts. Denosumab treatment of postmenopausal women with low bone mass reduces bone remodeling and increases bone mineral density (BMD). In women with postmenopausal osteoporosis, denosumab therapy significantly reduced the risk of new vertebral, hip, and nonvertebral fractures at 3 years compared with placebo. This agent has received regulatory approval in many countries for treating women with postmenopausal osteoporosis at increased risk or high risk for fracture.

The concept of a therapy designed to target a critical enzyme in the osteoclast bone resorption pathway is being translated into a very interesting and attractive potential approach to the management of osteoporosis. Moreover, cathepsin K inhibition seems to demonstrate a quality that is not present among other classes of anti $\neg$ resorptive agent - namely greater suppression of bone 
resorption than of bone formation. These features make cathepsin $\mathrm{K}$ inhibition a very promising intervention with which to treat osteoporosis. Despite initial difficul $\neg$ ties with the nonselective nature of the early cathepsin K inhibitors, more-selective cathep$\sin \mathrm{K}$ inhibition has reduced the potential for adverse events and drug-drug interactions, at least so far. Further ongoing studies are likely to shed more light on the long-term efficacy and safety of prolonged treatment with odanacatib. In conclusion, odanacatib is a cathepsin $\mathrm{K}$ inhibitor whose mechanism of action differs from that of other antiresorptive agents. It does not reduce the number of osteoclasts and does not alter their function, thereby offering theoretical advantages over bisphosphonates. The results of the phase III trial currently in development are required to confirm these possible advantages.

\section{R E F E R E}

1. Cauley JA. Public health impact of osteoporosis. J Gerontol A Biol Sci Med Sci. 2013 Oct;68(10):1243-51. doi: 10.1093/gerona/ glt093. Epub 2013 Jul 31.

2. Cauley JA, Chalhoub D, Kassem AM, et al. Geographic and etnic disparities in osteoporotic fractures. Nat Rev Endocrinol. 2014 Jun; 10(6):338-51. doi: 10.1038/nrendo.2014.51. Epub 2014 Apr 22.

3. Dhanwal DK, Dennison EM, Harvey NC, et al.Epidemiology of hip fracture worldwide geographic variation. Indian J Orthop. 2011 Jan;45(1):15-22. doi: 10.4103/00195413.73656.

4. Gallagher JC, Sai AJ. Molecular biology of bone remodeling: implications for new therapeutic target for osteoporosis. Maturitas. 2010 Apr;65(4):301-7. doi: 10.1016/j.maturitas.2010.01.002. Epub 2010 Jan 29.

5. Tanaka Y, Nakayamada S, Okada Y. Osteoblasts and osteoclasts in bone remodeling and infalammation. Curr Drug Targets Inflamm Allergy. 2005 Jun;4(3):325-8. 6. Fakhry M, Hamade E, Badran B, et al. Molecular mechanisms of mesenchymal stem cell differentiation towards osteoblasts. World J Stem Cells. 2013 Oct 26;5(4):136-48. doi: $10.4252 /$ wjsc.v5.i4.136.

7. James AW. Review of signaling pathway governing MSC osteogenic and adipogenic differentiation. Scientifica (Cairo).

2013;2013:684736. doi: 10.1155/2013/ 684736. Epub 2013 Dec 12.

8. Komori T. Regulation of osteoblast differentiation by RUNX2. Adv Exp Med Biol. 2010;658:43-9. doi: 10.1007/978-1-44191050-9_5.

9. Martin IJ, Sims NA. Signaling in bone. In: Seibel MT, Robin SP, Bilezikian JP, editors. Dynamics of bone and cartilage metabolism. $2^{\text {nd }}$ edition. Academic Press; 2010. P. 259-67. 10. Komori T. Cbfa1 is a master gene for osteoblast differentiation. In: Takahashi HE, editor. Mechanical loading of bone joints. $2^{\text {nd }}$ edition. Springer Verlag; 2012. P. 295-305. 11. Zhu F, Friedman MS, Luo W, et al. The transcription factor osterix (SP7) regulates BMP6-induced human osteoblast differentiation. J Cell Physiol. 2012 Jun;227(6):2677-85. doi: 10.1002/jcp.23010.

12. Komori T. Regulation of bone development and extracellular matrix protein genes by RUNX2. Cell Tissue Res. 2010 Jan;339(1):189-95. doi: 10.1007/s00441-0090832-8. Epub 2009 Aug 1.

13. Carbonare D, Innamorati G, Valenti MT. Transcription factor RUNX2 and its applica- tion to bone tissue engineering. Stem Cell Rev. 2012 Sep;8(3):891-7. doi: 10.1007/s12015011-9337-4.

14. Marie PJ, Kassem M. Osteoblasts in osteoporosis: past, emerging, and future anabolic targets. Eur J Endocrinol. 2011 Jul;165(1):1-10. doi: 10.1530/EJE-11-0132. Epub 2011 May 4.

15. Neve A, Corrado A, Cantatore FP. Osteoblast physiology in normal and pathological conditions. Cell Tissue Res. 2011 Feb;343(2):289-302. doi: 10.1007/s00441010-1086-1. Epub 2010 Dec 1.

16. Kruger T, Miller AH, Godwin AK, et al. Bone sialoprotein and osteopontin in bone metastasis of osteotropic cancers. Crit Rev Oncol Hematol. 2014 Feb;89(2):330-41. doi: 10.1016/j.critrevonc.2013.08.013. Epub 2013 Sep 7.

17. Bouet G, Bouleftour W, Juignet L, et al. The impairment of osteogenesis in bone sialoprotein (BSP) knockout calvaria cell cultures in cell dependent. PLoS One. $2015 \mathrm{Feb}$ 24;10(2):e0117402. doi: 10.1371/journal.pone. 0117402. eCollection 2015.

18. Lee YM, Fujukado N, Manaka H, et al. IL-1 plays an important role in the bone metabolism under physiological conditions. Int Immunol. 2010 Oct;22(10):805-16. doi: 10.1093/intimm/dxq431. Epub 2010 Aug 2. 19. Lombardi G, DiSomma C, Rubino M, et al. The roles of parathyroid hormone in bone remodeling: prospects for novell therapeutics. J Endocrinol Invest. $2011 \mathrm{Jul} ; 34$ (7 Suppl):18-22.

20. Van de Peppel J, Van Leeuwen JP. Vitamin D gene networks in human osteoblasts. Front Physiol. 2014 Apr 9;5:137. doi: 10.3389/fphys.2014.00137. eCollection 2014. 21. Almedia M, Iyer S, Martin-Millan M, et al. Estrogen receptor- $\alpha$ signaling in osteoblast progenitors stimulates control bone accrual. J Clin Invest. 2013 Jan;123(1):394-404. doi: 10.1172/JCI65910. Epub 2012 Dec 10. 22. Raggatt LJ, Partridge NC. Cellular and molecular mechanisms of bone remodeling. J Biol Chem. 2010 Aug 13;285(33):25103-8. doi: 10.1074/jbc.R109.041087. Epub 2010 May 25. 23. Sagalovsky S. Bone remodeling:cellularmolecular biology and cytokine RANKRANKL-osteoprotegerin (OPG) system and growth factors. Cream J Exptl Clin Med. 2013; 3(1-2):36-44

24. Hofbauer L, Rachner T. Die rolle des RANKL-RANK-OPG-Sygnalwegs in Knochenstoffwechsel. Forbildung Osteologie. 2010; 3(8):118-21
25. Rucci N. Molecular biology of bone remodeling. Clin Cases Miner Bone Metab. 2008 Jan;5(1):49-56.

26. Wright HL, McCarthy HS, Middleton J, et al. RANK, RANKL and osteoprotegerin in bone biology and disease. Curr Rev Musculoskelet Med. 2009 Mar;2(1):56-64. doi: 10.1007/s12178-009-9046-7. Epub 2009 Mar 10. 27. Kohli SS, Kohli VS. Role of RANKLRANK/osteoprotegerin molecular complex in bone remodeling and its immunopathologic implications. Indian J Endocrinol Metab. 2011 Jul;15(3):175-81. doi: 10.4103/22308210.83401 .

28. Weitzmann MN. The role of inflammatory cytokines, the RANKL/OPG axis, and the immunoskeletal interface in physiological bone turnover and osteoporosis. Scientifica (Cairo). 2013;2013:125705. doi: 10.1155/ 2013/125705. Epub 2013 Feb 3.

29. Takahashi N, Udagawa N, Suda T. Vitamin D, endocrine system and osteoclast. Bonekey Rep. 2014 Feb 5;3:495. doi: 10.1038/ bonekey.2013.229. eCollection 2014. 30. Marie PJ, Miraoui H, Severe N. FGF/FGFR signaling in bone formation: progress and perspectives. Growth Factors. 2012 Apr;30(2):117-23. doi: 10.3109/089 77194.2012.656761. Epub 2012 Feb 1. 31. Kato S. Hormones and osteoporosis update. Estrogen and bone remodeling. Clin Calcium. 2009 Jul;19(7):951-6. doi: CliCa0907951956.

32. Chen G, Dong C, Li YP. TGF- $\beta$ and BMP signaling in osteoblast differentiation and bone formation. Int $J$ Biol Sci. 2012;8(2):272-88. doi: 10.7150/ijbs. 2929. Epub 2012 Jan 21.

33. Lee K, Kim H, Park HS, et al. Targeting of the osteoclastogenesis RANKL-RANK axis prevents osteoporotic bone loss and soft tissue calcification in $\mathrm{C}$ oxsackievirus B3-ifected mice. J Immunol. $2013 \mathrm{Feb}$ 15;190(4):1623-30. doi: 10.4049/jimmunol.1201479. Epub 2013 Jan 9. 34. Lee MS, Kim HS, Yeon JT, et al. GM-CSF regulates fusion og mononuclear osteoclasts into bone-resorbing osteoclasts by activating the Ras/ERK pathway. J Immunol. 2009 Sep 1;183(5):3390-9. doi: 10.4049/jimmunol.0804314. Epub 2009 Jul 29.

35. Sims NA, Martin J. Coupling the activaties of bone formation and resorption: a multitude of signals within the basic multicellular unit. Bonekey Rep. 2014 Jan 8;3:481. doi: 10.1038/bonekey.2013.215. eCollection 2014. 
36. Takayanagi $\mathrm{H}$. The role of NFAT in osteoclast formation. Ann N Y Acad Sci. 2007 Nov;1116:227-37.

37. Datta HK, Ng WF, Walker JA, et al. The cell biology of bone metabolism. J Clin Pathol. 2008 May;61(5):577-87. doi: 10.1136/jcp.2007.048868.

38. Kang MA, Jo SA, Yoon YD, et al. Agelasine D suppresses RANKL-induced osteoclastogenesis via down-regulation of cfos, NFATc1 and NF-kB. Mar Drugs. 2014 Nov 24;12(11):5643-56. doi: 10.3390/md 12115643.

39. Marino S, Logan JG, Mellis D, et al. Generation and culture of osteoclasts. Bonekey Rep. 2014 Sep 10;3:570. doi: 10.1038/bonekey.2014.65. eCollection 2014. 40. Zou W, Teitelbaum SL. Integrins, growth factors, and the osteoclast cytoskeleton. Ann N Y Acad Sci. 2010 Mar;1192:27-31. doi: 10.1111/j.1749-6632.2009.05245.x. 41. Baron R, Horne W. Regulation of osteoclast activity. In: Bronner F,

Farach-Carson MC, Rubin J, editors. Bone resorption. Topics in bone biology. Vol 2. London; Springer Verlag; 2005. P. 34-57 42. Ross FP. Osteoclast biology and bone resorption. Bone Miner Res. 2008;12(1):16-22 43. Florencio-Silva R, Sasso GR, Sasso-Cerri E, et al. Biology of bone tissue: structure, function, and factors that influence bone cell. Biomed Res Int. 2015;2015:421746. doi: 10.1155/2015/421746. Epub 2015 Jul 13. 44. Shinohara C, Yamashita K, Matsuo T, et al. Effects of carbonic anhydrase inhibitor acetazolamide (AZ) on osteoclasts and bone structure. J Hard Tissue Biol. 2007;16(3):115-23 45. Nampoothiri S, Anikster Y. Carbonic anhydrase II deficiency: a novel mutation. Indian Pediatr. 2009 Jun;46(6):532-4. 46. Turk V, Stoka V, Vasiljeva O, et al. Cysteine cathepsins: from structure, function and regulation to new frontiers. Biochim
Biophys Acta. 2012 Jan;1824(1):68-88. doi: 10.1016/j.bbapap.2011.10.002. Epub 2011 Oct 12.

47. Xue Y, Cai T, Shi S, et al. Clinical and animal research findings in pycnodysostosis and gene mutation of cathepsin K from 1996 to 2011. Orphanet J Rare Dis. 2011 May 10;6:20. doi: 10.1186/1750-1172-6-20. 48. Sobacchi C, Schulz A, Coxon FP, et al. Osteopetrosis: genetics, treatment and new insights into osteoclast function. Nat Rev Endocrinol. 2013 Sep;9(9):522-36. doi: 10.1038/nrendo.2013.137. Epub 2013 Jul 23. 49. Nikitinskaya OA, Toroptsova NV. Denosumab is the first gene engineered agent for the treatment of osteoporosis. Modern Rheumatology Journal. 2012;6(3):68-73. DOI: http://dx.doi.org/10.14412/1996-7012-2012-751 50. Gamsjä ger M, Resch H. Cathepsin K antagonists: preclinical and clinical data. Wien Med Wochenschr. 2015 Feb;165(34):65-70. doi: 10.1007/s10354-014-0336-3. Epub 2015 Jan 9.

51. Papapoulos S, Chapurlat R, Libanati C, et al. Five years of denosumab exposure in women with postmenopausal osteoporosis: results from the first two years of FREEDOM extension. J Bone Miner Res. 2012

Mar;27(3):694-701. doi: 10.1002/jbmr.1479. 52. Chapurlat RD. Odanacatib: a review of its potential in the management of osteoporosis in postmenopausal women. Ther $A d v$ Musculoskelet Dis. 2015 Jun;7(3):103-9. doi: 10.1177/1759720X15580903. 53. $\mathrm{Ng} \mathrm{KW}$. Potential role of odanacatib in the treatment of osteoporosis. Clin Interv Aging. 2012;7:235-47. doi: 10.2147/CIA. S26729. Epub 2012 Jul 12.

54. Bonnick S, De Villiers T, Odio A, et al. Effects of odanacatib on BMD and safety in the treatment of osteoporosis in postmenopausal women previously treated with alendronate: a randomized placebo-con- trolled trial. J Clin Endocrinol Metab. 2013 Dec;98(12):4727-35. doi: 10.1210/jc.20132020. Epub 2013 Sep 24.

55. Engelke K, Fuerst T, Dardzinski B, et al. Odanacatib treatment trabecular and cortical bone in the femur of postmenopausal women: results of a two-year placebo-controlled trial. J Bone Miner Res. 2015 Jan;30(1):30-8. doi: 10.1002/jbmr.2292.

56. Langdahl B, Binkley N, Bone H, et al. Odanacatib in the treatment of postmenopausal women with low bone mineral density: five years of continued therapy in a phase II study. J Bone Miner Res. 2012 Nov;27(11):2251-8. doi: 10.1002/jbmr.1695. 57. Shiwaku Y, Neff L, Nagano K, et al. The crosstalk between osteoclasts and osteoblasts in dependent upon the composition and structure of biphasic calcium phosphates. PLoS One. 2015 Jul 20;10(7):e0132903. doi: 10.1371/journal.pone.0132903. eCollection 2015.

58. Cusick T, Chen CM, Pennypacker BL, et al. Odanacatib treatment increases hip bone mass and cortical thickness by preserving endocortical bone formation and stimulating periosteal bone formation in ovariectomized adult rhesus monkey. J Bone Miner Res. 2012 Mar;27(3):524-37. doi: 10.1002/jbmr. 1477. 59. Bone HG, Dempster DW, Eisman JA, et al. Odanacatib for the treatment of postmenopausal osteoporosis: development hystory and desing and participant characteristics of LOFT, the long-term odanacatib fracture trial. Osteoporos Int. 2015 Feb;26(2):699-712. doi: 10.1007/s00198-014-2944-6. Epub 2014 Nov 29.

60. Zerbini CAF, McClung MR. Odanacatib in postmenopausal women with low bone mineral density: a review of current clinical evidence. Ther Adv Musculoskelet Dis. 2013 Aug;5(4):199-209. doi: 10.1177/1759720X 13490860 .

\section{Author's information}

Dolzhenko A.T. is a Professor, MD, PhD and Doc.med. Sci., Head of the Institute Molecular Medicine. His research focuses on crosstalk and cooperatively of RANKL-RANK-OPG signaling with other signaling pathways with an emphasis on bone diseases.

Sagalovsky S. is MD and Head of the Orthopedic Division at the Clinic Median. His research focuses on aspects of inflammation with a focus on NF-kB signaling.

\section{Backmatter}

Acknowledgments

This work was supported in part by grant (P23690) from Martin-Luther University.

Author's contribution

All authors read and approved the final manuscript.

Competing interest

The authors declare no conflict of interest. 